\title{
Molecular and crystal structure of cyanoformamide
}

\section{U. Drück}

Institut für Mineralogie, Petrologie und Kristallographie,

Philipps-Universität, Lahnberge, D-3550 Marburg, Federal Republic of Germany

W. Becker and G. Becker

Institut für Anorganische Chemie der Universität,

Pfaffenwaldring 55, D-7000 Stuttgart 80, Federal Republic of Germany

Received: December 9, 1983

\section{Cyanoformamide / Crystal structure}

Abstract. $\mathrm{C}_{2} \mathrm{H}_{2} \mathrm{~N}_{2} \mathrm{O}, \quad M=70.051 ;$ Pnma $; a=8.519(6), \quad b=5.427(4)$, $c=7.235(5) \AA ; Z=4 ; D_{x}=1.391 \mathrm{~g} \cdot \mathrm{cm}^{-3} ; V=334.49 \AA^{3} ;(\mathrm{MoK} \alpha)=0.71069 \AA$; $\mathrm{F}(000)=144$. The structure was solved with direct methods and refined by least-squares analysis to an $R=0.059$ including 363 observed reflections. The molecule lies on the mirror plane and must therefore be completely planar. By two intermolecular hydrogen bridges towards the oxygen and the nitrogen atom of the carbonyl and the nitrile group respectively, neighbouring molecules of the same layer are bound together.

\section{Introduction}

Carrying on our studies on the electron density distribution of acyl amides, nitriles and their derivatives, similar work on 2,4,6-tricyano-s-triazine which can best be prepared from the corresponding amide and diphosphorus pentoxide (Bailey et al., 1963), has been planned. We found, however, that the product of this synthesis when condensed onto a liquid-nitrogen-cooled glass finger, contains considerable amounts of a second more volatile compound. Separation can be accomplished by renewed sublimation yielding colourless, prismatic crystals which slowly turn yellow, when exposed to light or to X-ray radiation. The X-ray structure determination showed this compound to be cyanoformamide (ureamononitrile), formed by monomerization of the starting triazine; this substance, incorporated into many insectizides, can be synthesized in very high yield from cyanogen, water, formic acid, and acetonitrile (Welcher et al., 1959). 
Table 1. Fractional coordinates, anisotropic temperature factors $U_{i j}{ }^{2}\left(\cdot 10^{3} ; \AA^{2}\right)$ of the nonhydrogen atoms as well as fractional coordinates and isotropic $B$-values $\left(\AA^{2}\right)$ of the hydrogen atoms

\begin{tabular}{llllllllll}
\hline Atom & $x$ & $y$ & $z$ & $U_{11}$ & $U_{22}$ & $U_{33}$ & $U_{12}$ & $U_{13}$ & $U_{23}$ \\
\hline $\mathrm{C}(1)$ & $0.2406(6)$ & 0.2500 & $0.6026(7)$ & $28(3)$ & $40(3)$ & $24(2)$ & 0 & $-1(2)$ & 0 \\
$\mathrm{C}(2)$ & $0.1281(6)$ & 0.2500 & $0.4473(8)$ & $33(3)$ & $42(3)$ & $33(3)$ & 0 & $-2(2)$ & 0 \\
$\mathrm{~N}(1)$ & $0.3899(5)$ & 0.2500 & $0.5501(7)$ & $28(2)$ & $60(3)$ & $24(2)$ & 0 & $1(2)$ & 0 \\
$\mathrm{~N}(2)$ & $0.0361(7)$ & 0.2500 & $0.3325(7)$ & $50(3)$ & $60(4)$ & $43(3)$ & 0 & $-19(3)$ & 0 \\
$\mathrm{O}(1)$ & $0.1914(5)$ & 0.2500 & $0.7603(6)$ & $33(2)$ & $81(3)$ & $26(2)$ & 0 & $5(2)$ & 0 \\
\hline Atom & $x$ & $y$ & $z$ & $B$ & & & & & \\
\hline $\mathrm{H}(1)$ & $0.406(7)$ & 0.250 & $0.431(10)$ & $1.4(10)$ & & & & \\
$\mathrm{H}(2)$ & $0.463(10)$ & 0.250 & $0.642(11)$ & $3.5(20)$ & & & & & \\
\hline
\end{tabular}

- The temperature factor $T$ is given by the equation: $T=\exp \left(-2 \pi^{2}\left[U_{11} \cdot h^{2} \cdot a^{* 2}+\ldots\right.\right.$ $\left.\left.+2 \cdot U_{23} \cdot k \cdot l \cdot b^{*} \cdot c^{*}\right]\right)$.

\section{Data collection}

5624 reflections, $0.049<\sin \theta / \lambda<0.65 \AA^{-1}$, MoK $\alpha, \omega / 2 \theta$ scan mode; fourcycle diffractometer Stoe AED, temperature of measurement $+20^{\circ} \mathrm{C} ; 421$ independent reflections, internal reliability factor for 302 reflections observed $(I>2 \sigma(I))$ being 0.053 ; no absorption correction; scattering factors for neutral atoms (International Tables, 1974). The cell constants were determined and refined by a least-squares calculation using the positions of a selected number of 18 reflections.

\section{Structure determination}

The structure was solved with the MULTAN 80 program system (Main et al., 1980). Refinements of the non-hydrogen atoms for both possible space groups showed the centrosymmetric space group to be the correct solution. At this stage of refinement the resulting difference-density map revealed the positions of both hydrogen atoms. Further refinement with isotropic and anisotropic temperature factors for the hydrogen and all the other atoms respectively, gave the following results: $R=0.059 ; R_{w}=0.07\left[w=1 / \sigma^{2}\left(F_{0}\right)\right]$, G.o.F. $=1.24$. In Tables 1 and 2 the final parameters as well as the intramolecular bond lengths and angles have been listed, Figure 1 shows an ORTEP-plot of the molecule ${ }^{1}$.

\footnotetext{
${ }^{1}$ Additional material to this paper can be ordered referring to the number CSD 50747, names of the authors and citation of the paper at the Fachinformationszentrum Energie Physik Mathematik, D-7514 Eggenstein-Leopoldshafen 2, FRG
} 
Table 2. Bond lengths $(\AA)$ and angles $\left(^{\circ}\right)$ with standard deviations $s^{\star}$ for $\mathrm{C}_{2} \mathrm{H}_{2} \mathrm{~N}_{2} \mathrm{O}$

\begin{tabular}{llll}
\hline $\mathrm{C}(1)-\mathrm{N}(1)$ & $1.327(7)$ & $\mathrm{N}(1)-\mathrm{C}(1)-\mathrm{O}(1)$ & $126.8(5)$ \\
$\mathrm{C}(1)-\mathrm{O}(1)$ & $1.216(6)$ & $\mathrm{N}(1)-\mathrm{C}(1)-\mathrm{C}(2)$ & $113.9(4)$ \\
$\mathrm{C}(1)-\mathrm{C}(2)$ & $1.477(8)$ & $\mathrm{O}(1)-\mathrm{C}(1)-\mathrm{C}(2)$ & $119.3(5)$ \\
$\mathrm{C}(2)-\mathrm{N}(2)$ & $1.141(8)$ & $\mathrm{C}(1)-\mathrm{C}(2)-\mathrm{N}(2)$ & $177.2(6)$ \\
$\mathrm{N}(1)-\mathrm{H}(1)$ & $0.87(7)$ & $\mathrm{C}(1)-\mathrm{N}(1)-\mathrm{H}(1)$ & $116(4)$ \\
$\mathrm{N}(1)-\mathrm{H}(2)$ & $0.91(8)$ & $\mathrm{C}(1)-\mathrm{N}(1)-\mathrm{H}(2)$ & $116(5)$ \\
& & $\mathrm{H}(1)-\mathrm{N}(1)-\mathrm{H}(2)$ & $128(6)$ \\
\hline
\end{tabular}

- Standard deviations of bond lengths and angles were calculated taking into account uncertainties of cell parameters and fractional coordinates both

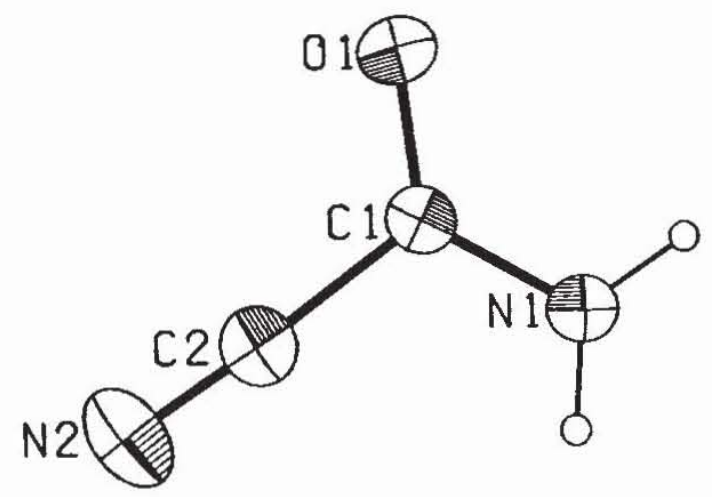

Fig. 1. ORTEP-plot of a molecule of cyanoformamide. The thermal ellipsoids have been scaled to $50 \%$ probability
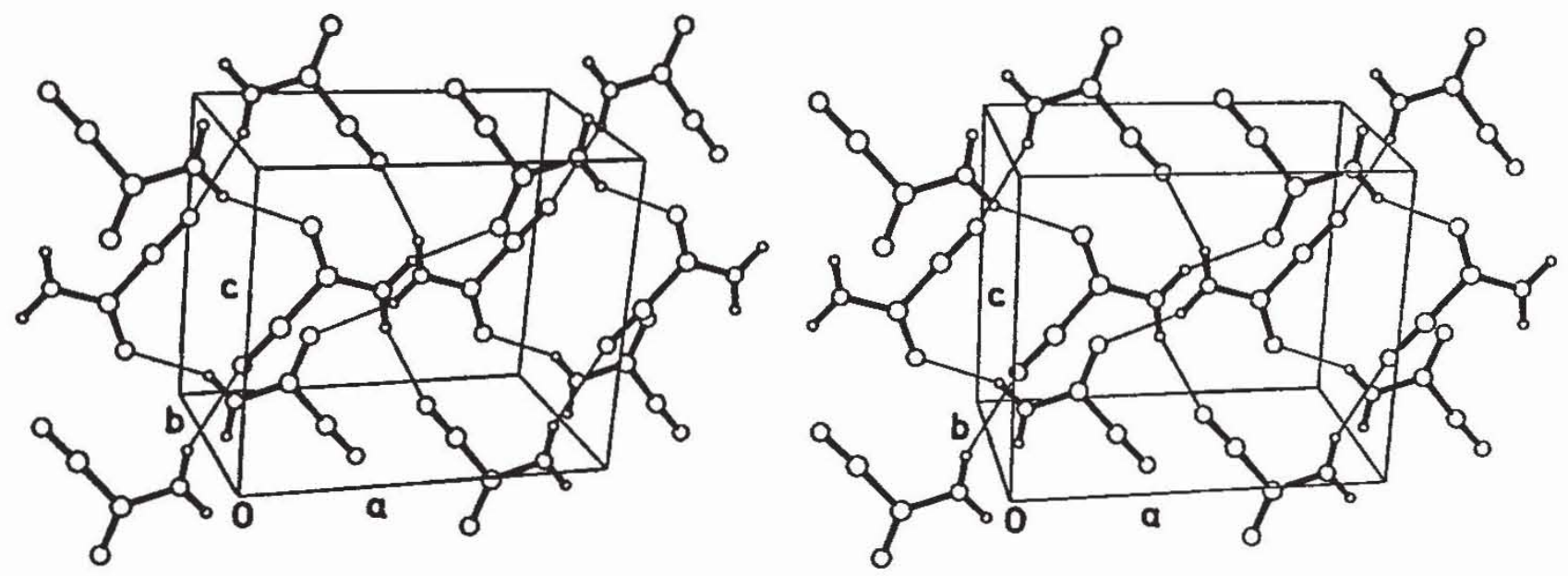

Fig. 2. Packing of molecules in solid cyanoformamide

\section{Discussion}

A comparison with the well known structures of urea (Guth et al., 1980) and thiourea (Kutoglu et al., 1982) reveals a good correspondence in view of the $\mathrm{C}(1)-\mathrm{N}(1)$ bond length of the amide group [1.327(7) vs. 1.333(1) or $1.334(2) \AA]$; the $\mathrm{C}(1)-\mathrm{O}(1)$ bond, hỏwever, is considerably shorter [1.216(6) vs. $1.246(2) \AA]$. Probably due to less steric interactions on the nitrile side of this planar molecule the angle $\mathrm{O}(1)-\mathrm{C}(1)-\mathrm{N}(1)$ widens [126.8(5) vs. 
121.9(1) $)^{\circ}$, whereas the angle $\mathrm{N}(1)-\mathrm{C}(1)-\mathrm{C}(2)$ between the amide and the nitrile group is smaller than the corresponding $\mathrm{N}-\mathrm{C}-\mathrm{N}$ value in the urea molecule [113.9(4) vs. $\left.116.2(1)^{\circ}\right]$.

The nitrile group shows the well known 'shortening' of its bond length from about 1.16 to $1.141(8) \AA$ which is always observed in case of conventional (free atom model) refinement (Drück and Guth, 1982). A small deviation from linearity $\left[177.2(6)^{\circ}\right]$ of the bond angle $C(1)-C(2)-N(2)$ might be an effect of intermolecular hydrogen bonding. A C(1) $-\mathrm{C}(2)$ distance of $1.477(8) \AA$ is expected for a bond between a $\mathrm{sp}^{2}$ - and a sphybridized carbon atom.

Figure 2 shows the crystal structure of cyanoformamide which is characterized by isolated layers parallel to (010). Sixteen-membered rings formed from four molecules each, are stabilized by two $\mathrm{N}-\mathrm{H} \cdots \mathrm{O}$ and two $\mathrm{N}-\mathrm{H} \cdots \mathrm{N}$ hydrogen bridges. With values of $2.07(8) \AA$ for $\mathrm{H}(2)-\mathrm{O}\left(1^{\prime}\right)\left(\frac{1}{2}+x, \frac{1}{2}-y\right.$, $\left.\frac{3}{2}-z\right)$ and $2.21(7) \AA$ for $\mathrm{H}(1)-\mathrm{N}\left(2^{\prime \prime}\right)\left(\frac{1}{2}+x, \frac{1}{2}-y, \frac{1}{2}-z\right)$ both intermolecular hydrogen bonds are considerably shorter than the sums of the van der Waals radii $(2.70,2.59 \AA$ : Bondi, 1964). The bond angles at the bridging hydrogen atoms are 153(5) and 159(4) degrees, the $\mathrm{N}(1) \cdots \mathrm{O}\left(1^{\prime}\right)$ and $\mathrm{N}(1) \cdots \mathrm{N}\left(2^{\prime \prime}\right)$ contact has found to be 2.91 and $3.04 \AA$, respectively.

All computations were done with an IBM 370/145 computer at Mineralogisches Institut der Universität Marburg using the X-ray system (Stewart et al., 1970).

Financial support of Deutsche Forschungsgemeinschaft is gratefully acknowledged.

\section{References}

Bailey, A. S., Henn, B. R., Langdon, J. M.: Molecular complexes of aromatic nitrles. Tetrahedron 19, $161-167$ (1963)

Bondi, A.: Van der Waals volumes and radii. J. Phys. Chem. 68, $441-451$ (1964)

Drück, U., Guth, H.: A new refinement of monoclinic tetracyanoethylene (TCNE) from X-ray and neutron data. Z. Kristallogr. 161, 103-110 (1982)

Guth, H., Heger, G., Klein, S., Treutmann, W., Scheringer, C.: Strukturverfeinerung von Harnstoff mit Neutronenbeugungsdaten bei 60,123 and $293 \mathrm{~K}$ und $\mathrm{X}-\mathrm{N}-$ und $X-X\left(1 \mathrm{~s}^{2}\right)$-Synthesen bei etwa $100 \mathrm{~K}$. Z. Kristallogr. 153, 237-254 (1980)

International Tables for X-ray Crystallography, vol. IV, p. 99 . Birmingham: Kynoch Press 1974

Johnson, C. K.: ORTEP, A Fortran thermal-ellipsoid plot program for crystal structure illustrations. Oak Ridge National Laboratory, Oak Ridge, Tennessee (1965)

Kutoglu, A., Scheringer, C., Meyer, H., Schweig, A.: Experimental and theoretical difference densities for thiourea. Refinement of electron density distributions with charge-cloud models. X. Comparison of observed and calculated electron densities. XIII. Acta Crystallogr. B38, 2626-2632 (1982)

Main, P., Fiske, S. J., Hull, S. E., Lessinger, L., Germain, G., Declercq, J.-P., Woolfson, M. M.: MULTAN 80, A system of computer programs for the automatic solution of crystal structures from X-ray diffraction-data. University of York (UK), York (1980)

Stewart, J. M., Kundel, F. A., Baldwin, J. C.: The X-ray system of crystallographic computer programs. Computer Science Center, University of Maryland, Maryland (1970)

Welcher, R. P., Castellion, M. E., Wystrach, V. P.: The preparation and reactions of 1cyanoformamide. J. Am. Chem. Soc. 81, 2541 -2547 (1959) 